

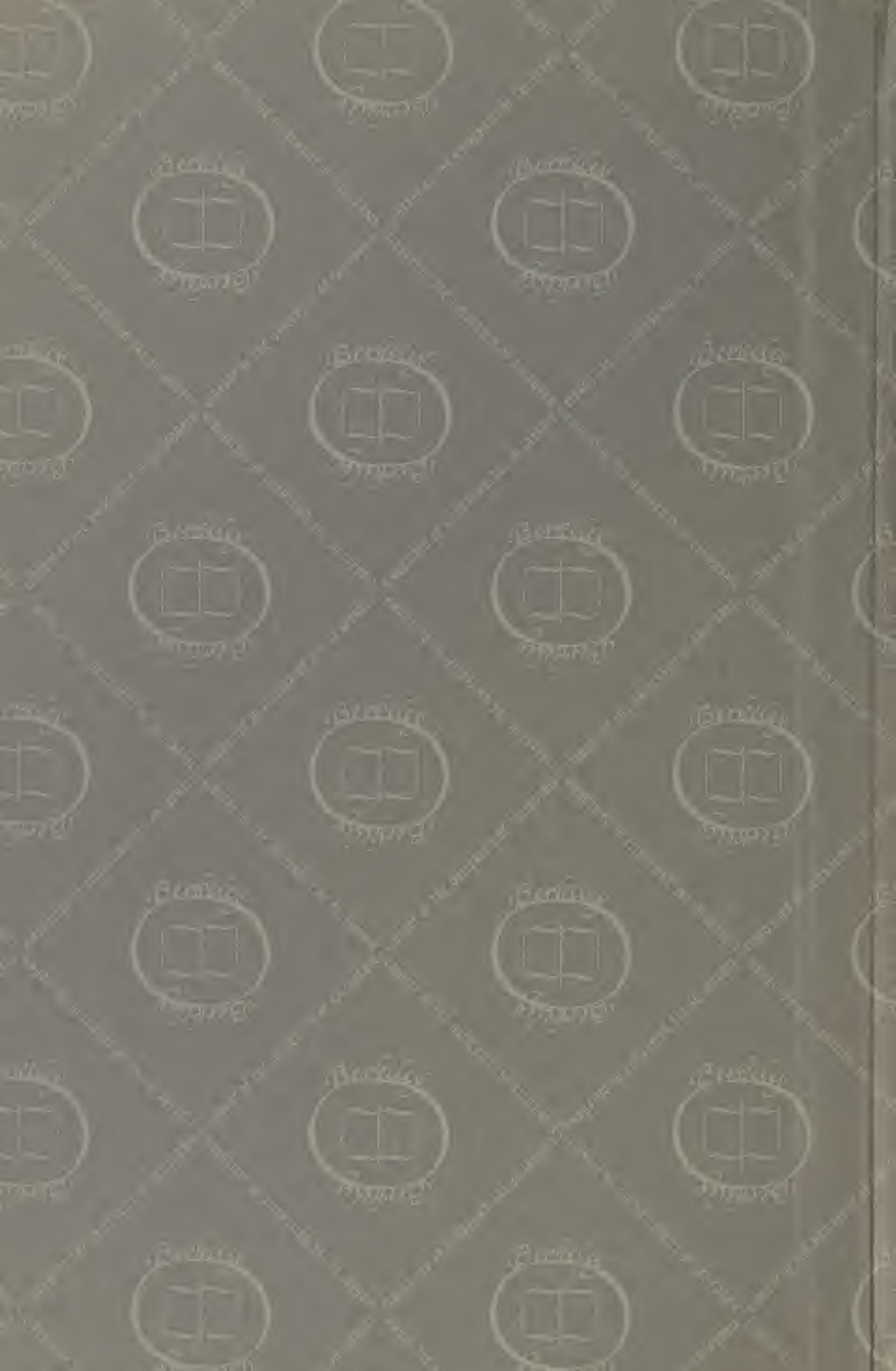




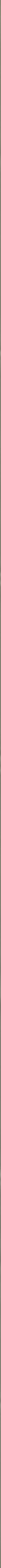




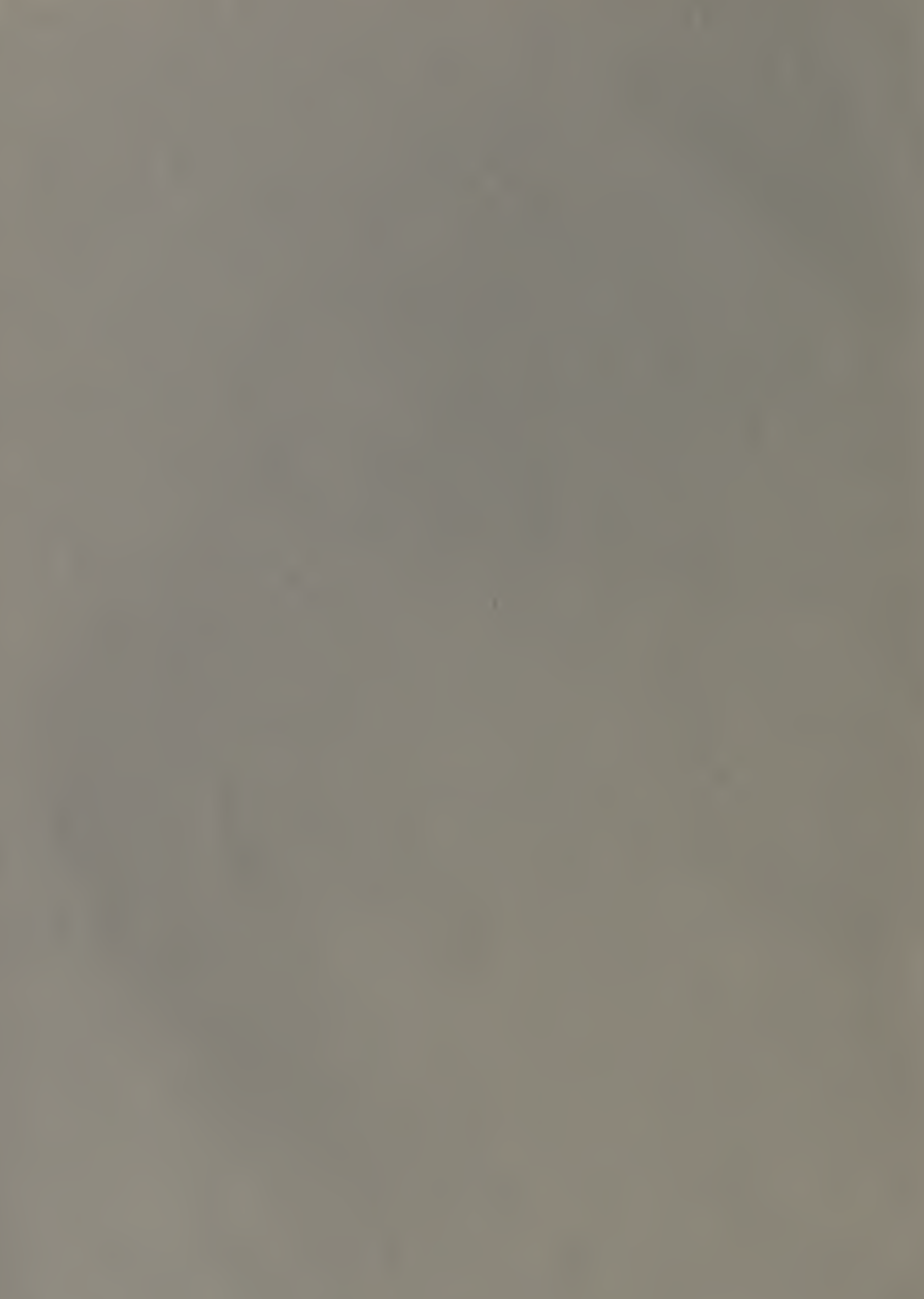

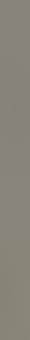


Digitized by the Internet Archive in 2008 with funding from Microsoft Corporation 



\section{THE DECENNIAL PUBLICATIONS OF THE UNIVERSITY OF CHICAGO}




\section{THE DECENNIAL PUBLICATIONS}

ISSUED IN COMMEMORATION OF THE COMPLETION OF THE FIRST TEN YEARS OF THE UNIVERSITY'S EXISTENCE

AUTHORIZED BY THE BOARD OF TRUSTEES ON THE RECOMMENDATION OF THE PRESIDENT AND SENATE

EDITED BY A COMMITTEE APPOINTED BY THE SENATE

EDWARD CAPPS

STARR WILLARD CUTTING

JAMES IROWLAND ANGELL

CARL DARLING BUCK

JULIUS STIEGLITZ
WILLIAM I. THOMAS

FREDERIC IVES CARPENTER

JACQUES LOEB SHAILER MATHEWS oskar bolza 
THESE VOLUMES ARE DEDICATED

TO THE MEN AND WOMEN

OF OUR TIME AND COUNTRY WHo BY WiSE AND GENERous GIVING

HAVE ENCOURAGED THE SEARCH AFTER TRUTH

IN ALL DEPARTMENTS OF KNOWLEDGE 



\section{INVESTIGATIONS}





\section{INVESTIGATIONS REPRESENTING THE DEPARTMENTS}

\section{ZOÖLOGY ANATOMY PHYSIOLOGY NEUROLOGY BO'TANY PA'THOLOGY BACTERIOLOGY}

THE DECENNIAL PUBLICATIONS FIRST SERIES VOLUME $\mathrm{X}$

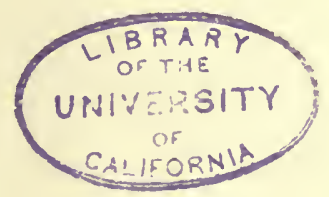

CHICAGO

THE UNIVERSITY OF CHICAGO PRESS 1903 
Copyright 1903

BY THE UNIVERSITY OF CHICAGO 


\section{CON'TEN'TS}

I. On the Production and Suppression of Muscular Twitchings and Hypersensitiveness of the Skin by Electrolytes - - By Jacques Loeb, Professor and Head of the Department of Physiology

II. On a Formula for Determining the Weight of the Central Nervous System of the Frog from the Weight and Length of

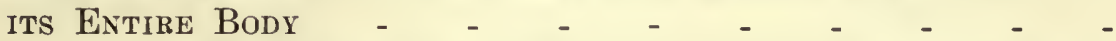

By Henry H. Donaldson, Professor and Head of the Department of Neurology

III. The Development of the Colors and Color Patterns of Coleoptera, with Observations upon the Development of Color in Other Orders of Insects (with Plates I-III) - _ -

By William Lawrence Tower, Assistant in Embryology

IV. The Artificial Production of Spores in Monas by a Reduction

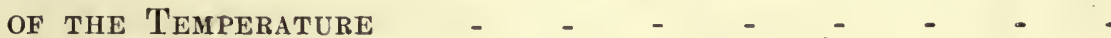

By Arthur W. Greelex, Assistant in Physiology

V. The Self-Purification of Streams $\quad-\quad-\quad-\quad-\quad-\quad-$

By Edwin Oakes Jordan, Associate Professor of Bacteriology

VI. The Lecithans: Their Function in the Life of the Cell By Waldemar Koch, Assistant in Pharmacology

VII. A Contribution to the Physical Analysis of the Phenonena of

Absorption of Liquids by Animal Tissues $-{ }^{-}$
By Ralph Waldo Webster, Assistant in Physiological Chemistry

ViII. The Distribution of Blood-Vessels in the Labyinth of the Ear of Sus Scrofa Donesticus (with Plates V-XII) - - -

By George E. Shambaugh, Instructor in Anatomy of the Ear, Nose, and Throat 
IX. The Animal Ecology of the Cold Spring Sand Spit, with Remarks

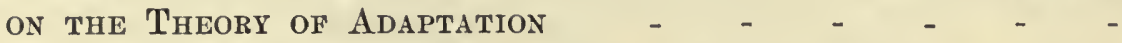

By Charles Benedict Davenport, Associate Professor of Zoölogy and Embryology

X. The Finer Structure of the Neurones in the Nervous System of the White Rat (with Plates XIII, XIV)

By Shiveishr Hatai, Research Assistant in Neurology

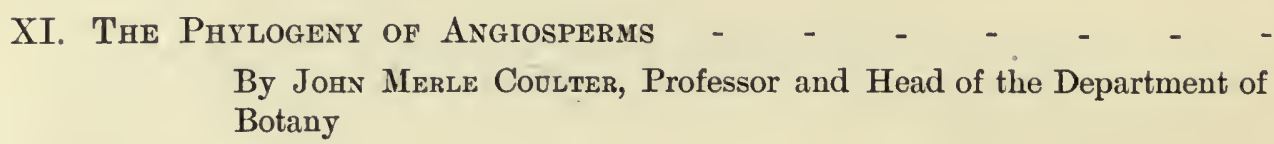

XII. Studies in Fat Necrosis

By H. Gideon Wells, Instructor in Pathology

XIII. Oogenesis in Saprolegnia (with Plates XV, XVI) - - -

By Bradlex Moore Davis, Assistant Professor of Botany [Holl BOTANICAL LABORATORY]

XIV. The Early Development of Lepidosteus Osseus (with Plates XVII, XVIII) - $\quad$ - $\quad$ - $\quad$ - $\quad$ - $\quad$ - $\quad$ - $\quad$ - $\quad$ -

By Albert Chadjcey Excleshymer, Assistant Professor of Anatomy

XV. The Structure of the Glands of Brunner (with Plates XIX-

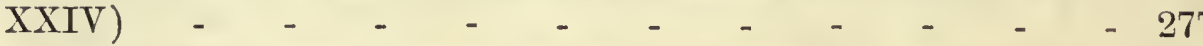

By Robert Russell Bensley, Assistant Professor of Anatomy

XVI. Mitosis in Pellia (with Plates XXV-XXVII) - $\quad$ - $\quad$ - 327

By Charles Joseph Chamberlain, Instructor in Morphology and Cytology

XVII. A Description of the Brains and Spinal Cord of Two Brothers Dead of Hereditary Ataxia. (Cases XVIII and XX of the Series in the Family Described by Dr. Sanger Brown); (with plates XXVIII-XXXIX) - $\quad$ - $\quad$ - $\quad$ - $\quad$ - $\quad$ -

By Lewellys Franklin Barker, Professor and Head of the Department of Anatomy. With an Introduction by Dr. SANGer Brown 


\section{THE PHYLOGENY OF ANGIOSPERMS}





\title{
'THE PHYLOGENY OF ANGIOSPERMS
}

\author{
Johi M. Coutter
}

ThE views presented in this paper are in the main based upon numerous investigations conducted by members of the botanical staff and graduate students. The accounts of these investigations, extending through a period of six years, have been published from time to time, chiefly in the Botanical Gazette, but their bearing upon the problem of the phylogeny of Angiosperms has never been presented. It would be confusing to cite the literature involved in this presentation, as it would mean an extensive bibliography and is in the main familiar to students of the Angiosperms. The purpose is to present in as compact form as possible the bearings of our present knowledge upon a problem of great obscurity. The phylogeny of any great group will probably always remain a baffling problem, incapable of actual demonstration, and yet theories of phylogeny serve to co-ordinate knowledge and stimulate investigation. It should be stated that when similarity of structure was taken to be a sure indication of genetic relationships, the problem promised an approximate solution. But since it has been proved that similar structures may develop independently, the difficulty of solution has become apparently insurmountable.

The first phase of the problem has to do with the common or independent origin of the Monocotyledons and Dicotyledons. The current view assumes their monophyletic origin, a view based largely upon the great uniformity of the peculiar development of the female gametophyte. It is argued that the independent origin of such exact details of development and structures is inconceivable. The peculiar female gametophyte of Angiosperms, however, has been found to vary enough to indicate that it is an extreme expression of tendencies evident in the heterosporous Pteridophytes and Gymnosperms; in other words, an ultimate result of heterospory. Further, nothing is more clear than that heterospory has originated independently in several plant groups; and the assumption that its ultimate expressions, the seed and the angiospermous female gametophyte, have been reached by only one line seems more than improbable.

This somewhat theoretical objection to the current argument in favor of the monophyletic origin of Angiosperms is strengthened by certain fundamental differences between the Monocotyledons and Dicotyledons. The differences in the development of the embryos of the two groups are hard to reconcile upon the theory of monophyletic origin. Recent investigations of all of those Dicotyledons that have been called "pseudo-monocotyledonous,". on account of their apparently terminal cotyledon and lateral stem-tip, have shown a normal dicotyledonous embryology with more or less complete abortion of one of the cotyledons and displacement of the stem-tip through the development of the functional cotyledon. Again, the differences in the structure 
of the stem and in the character of its vascular bundles are far more difficult to connect genetically than to refer to a polyphyletic origin, with all that that implies. One of the strongest arguments against the monophyletic theory comes from historical testimony. The "Proangiosperms" of the Lower Cretaceous, so far as known, appeared associated with undoubted Monocotyledons, and merged gradually into recognizable Dicotyledons, without indicating any relationship to the Monocotyledons. The emerging of Dicotyledons from this vague group either indicates that they originated independently, or that the Proangiosperms were transition forms between Monocotyledons and Dicotyledons. The latter alternative is inconceivable, especially since the most primitive Dicotyledons are now recognized to be more primitive than any of the Monocotyledons.

It is of interest to note that recent anatomical investigations contradict the current view that Monocotyledons are the more primitive, and Dicotyledons derived from them, and show, so far as the development of the vascular system is concerned, that Monocotyledons are derived from Dicotyledons in case they have a common phylogeny.

All the testimony available, morphological, historical, and anatomical, seems most consistent when interpreted in favor of the polyphyletic origin of Angiosperms.

The second phase of the problem is to determine whether the Angiosperms have been derived from Gymnosperms or from Pteridophytes. The general question is the same whether one believes in their monophyletic origin or not. The older view is that Angiosperms are phylogenetically related to Gymnosperms, and Gnetum has been regarded as the nearest living representative of a transition condition between Gymnosperms and Angiosperms. The argument is based upon such angiospermous characters in Gnetum as the absence of archegonia, the organization of eggs while the gametophyte consists only of free cells, the presence of a perianth and true vessels, and the dicotyledonous leaves. This showing is certainly strong, and especially in the structure of the embryo sac does Gnetum show characters that may well illustrate a stage in the Angiosperm phylum; but that it actually represents the group from which the Angiosperms were derived seems unlikely. In fact, the historical argument against such a claim is very strong, for there is no evidence that Gnetum or allied forms existed among the numerous Angiosperms of the Cretaceous and Tertiary. If it were related in any way to the origin of so dominant a group as the Angiosperms, it seems probable that it would have left some evidence of its existence. Nor is it of special avail to claim that fossil Gnetales may be found in the tropics or in the Southern Hemisphere, for the great uniformity of climate during early periods has left the records of tropical vegetation in the temperate and even boreal regions of today; so that the strata of the tropics are not likely to reveal prominent types of vegetation unrepresented in the strata of temperate regions.

The argument from the presence of a "perianth" is particularly vulnerable, since the structure so-called merely represents the bracts common among Gymnosperms, and 
the most primitive Angiosperms have no perianth. Further, the presence of true vessels in the secondary wood is an argument as much in favor of the origin of Angiosperms from certain heterosporous Pteridophytes as from Gnetum. Every indication points to the conclusion that Gnetum is a highly specialized and comparatively recent member of the Gymnosperm phylum, and as such could not have given rise to the Angiosperms.

If the Gymnosperms are not the ancestral forms of the Angiosperms, the direct derivation of the latter from Pteridophytes becomes a matter of course. Perhaps it was natural to turn at first to the heterosporous Pteridophytes, and among them the only forms that could seem to be within the range of probability are Selaginella and Isoetes. The latter has been persistently associated with the origin of the Monocotyledons, especially in connection with the former idea that Monocotyledons are the primitive Angiosperm stock. Any supporter of this view now would be almost forced to maintain the polyphyletic origin of Angiosperms. The most striking resemblance of Isoetes to the Monocotyledons occurs in the embryo, in which the single cotyledon is terminal and the stem-tip lateral. A thorough investigation of Isoetes, however, has developed so many difficulties in the way of accepting it as related in any way to the Monocotyledons that the theory must be regarded as untenable.

The only possible alternative as to the origin of Monocotyledons, in case they have arisen independently of the Dicotyledons, is to regard them as the end of a heterosporous line that developed independently from the eusporangiate Filicales, whose Pteridophyte members are extinct. Since several independent heterosporous lines are already recognized, it is not at all necessary to connect any seed-plants with living heterosporous Pteridophytes.

More important, however, seems to be the determination of the origin of the Dicotyledons, whether they represent an independent phylum or the primitive angiospermous stock. The fact that they emerged from the so-called "Proangiosperms," which were largely displayed in the earlier part of the lower Cretaceous, seems to be fairly well established. The question, therefore, has to do with the origin of the Proangiosperms. They do not seem to warrant the belief that they represent a common stock from which both Monocotyledons and Dicotyledons have been derived, for the Monocotyledons are believed to have existed in unmistakable forms before the large assemblage of Proangiosperms gave rise to unmistakable Dicotyledons. Still less conceivable is it that Proangiosperms represent the transition forms from Monocotyledons to Dicotyledons, for nothing in their known structure seems to suggest such a view. That they were derived from Gnetum-like forms is discredited by the fact that there is no sure record of the existence of Gnetum at such an early period, and to have given rise to such an assemblage of forms it must have been a conspicuous group.

If we turn to the earlier groups that were sufficiently prominent and at all suggestive of having given rise to the Proangiosperms, we encounter the Coniferales, Cycadales, Lycopodiales, and Filicales. The Gymnosperm origin of Dicotyledons 
seems to be most unlikely with the exclusion of Gnetum. At the same time, it might be claimed that Dicotyledons represent an independent line from the Gymnosperm stock, that advanced in the same direction and much farther than did the Gnetum line; but all the essential morphology of the Gymnosperms is less favorable to such an origin than is that of the heterosporous Pteridophytes.

The Lycopodiales certainly deserve serious consideration in this connection. The structures of Selaginella are about as suggestive of Dicotyledons as those of Isoetes are suggestive of Monocotyledons, the embryo being as distinctly dicotyledoncus as that of Isoetes is monocotyledonous, and our study of Selaginella has shown the strikingly seed-like character of the megasporangium. But a seed may be attained by any heterosporous line, and Selaginella and even its ancient Lycopodium stock have too many peculiarities to be considered seriously as ancestral types of Angiosperms.

The only other alternative is that mentioned in connection with the origin of the Monocotyledons, namely the derivation of the Proangiosperms as an independent heterosporous line from the abundant ancient eusporangiate Filicales, and this view is supported by anatomical testimony.

It is becoming increasingly evident that the great marattiaceous plexus of the Palæozoic probably gave rise to several heterosporous lines, one or more of which have certainly been responsible for the Gymnosperms, and others have led to the Angiosperms. As heterospory may lead to seed-formation in any line, it is inconceivable that only one or at most two of the numerous heterosporous lines have attained seed-production. It is more probable that the Angiosperms have arisen from the Marattia-like ferns in several independent lines; that the group known as Angiosperms is determined by its attainment of seed-production rather than its monophyletic origin; but that in a certain sense it has a common phylogeny and hence numerous characters in common.

A summary of these conclusions may be stated as follows :

1. The Monocotyledons and Dicotyledons comprise at least two independent angiospermous lines, and do not represent a single phylum.

2. No Angiosperm phylum has been derived from the Gymnosperms or from living heterosporous Pteridophytes.

3. All Angiosperm phyla have been derived as independent heterosporous lines from the ancient eusporangiate Filicales, which also gave rise to the Gymnosperms.

4. Several Angiosperm phyla probably arose independently from the marattiaceous plexus of the Palæozoic.

5. If Angiosperms have a monophyletic origin, which seems very unlikely, it seems clear that the Monocotyledons have been derived. from the more primitive Dicotyledons. 





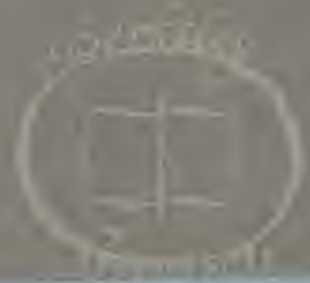

14 DAY USE

RETURN TO DESK FROM WHICH BORROWED

LOAN DEPT.

This book is due on the last date stamped below, or on the date to which renewed.

Renewed books are subject to immediate recall.

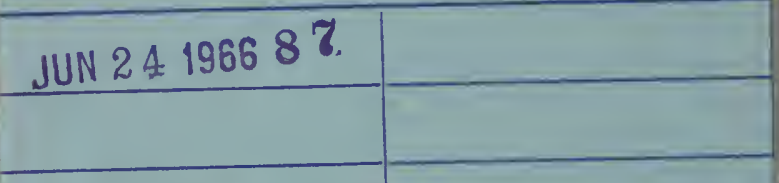

ONN $1066 \quad R C D$

APR 30196815

RECEIVED

MAY $7 \cdot 68-16$ AM
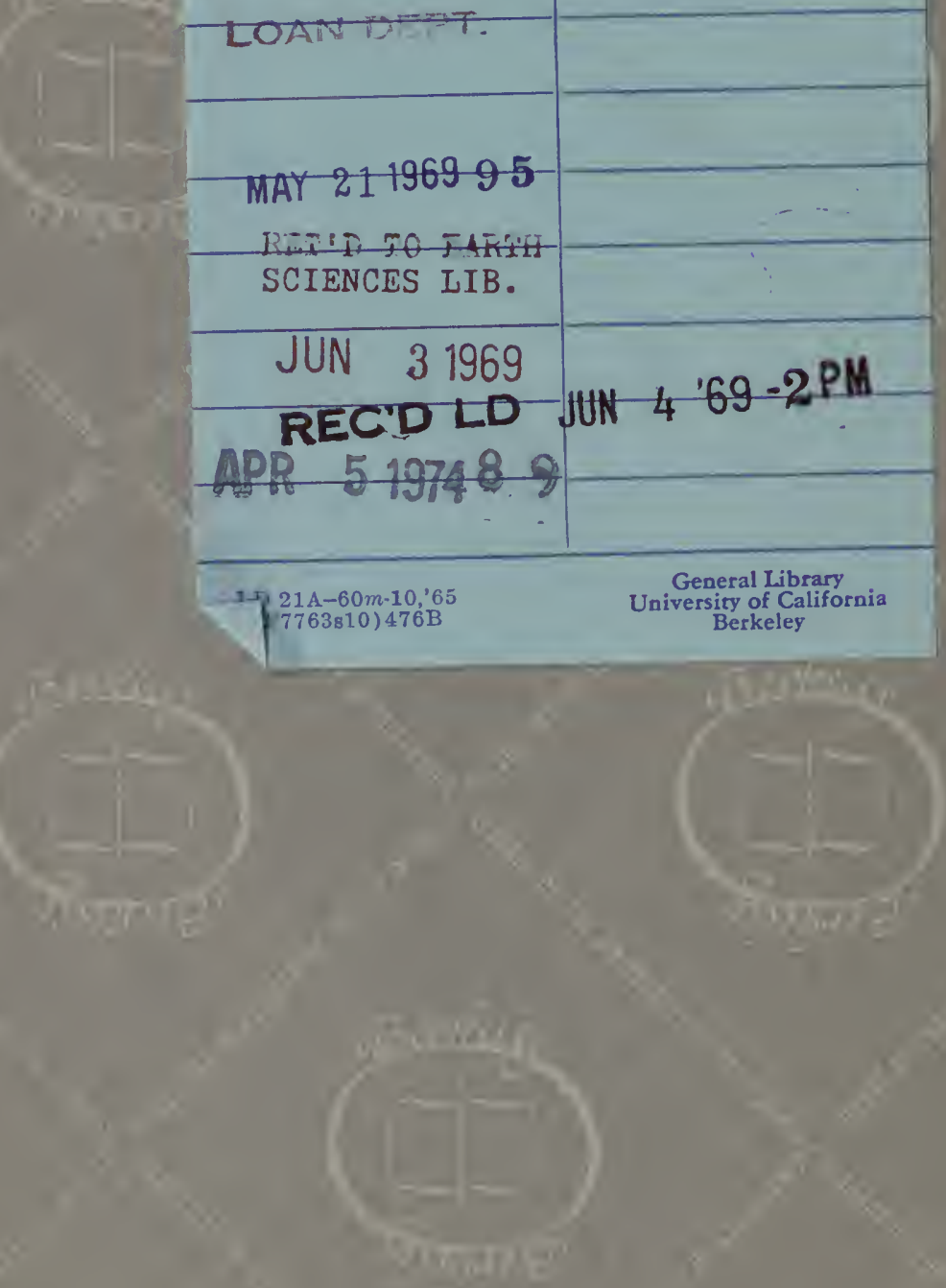


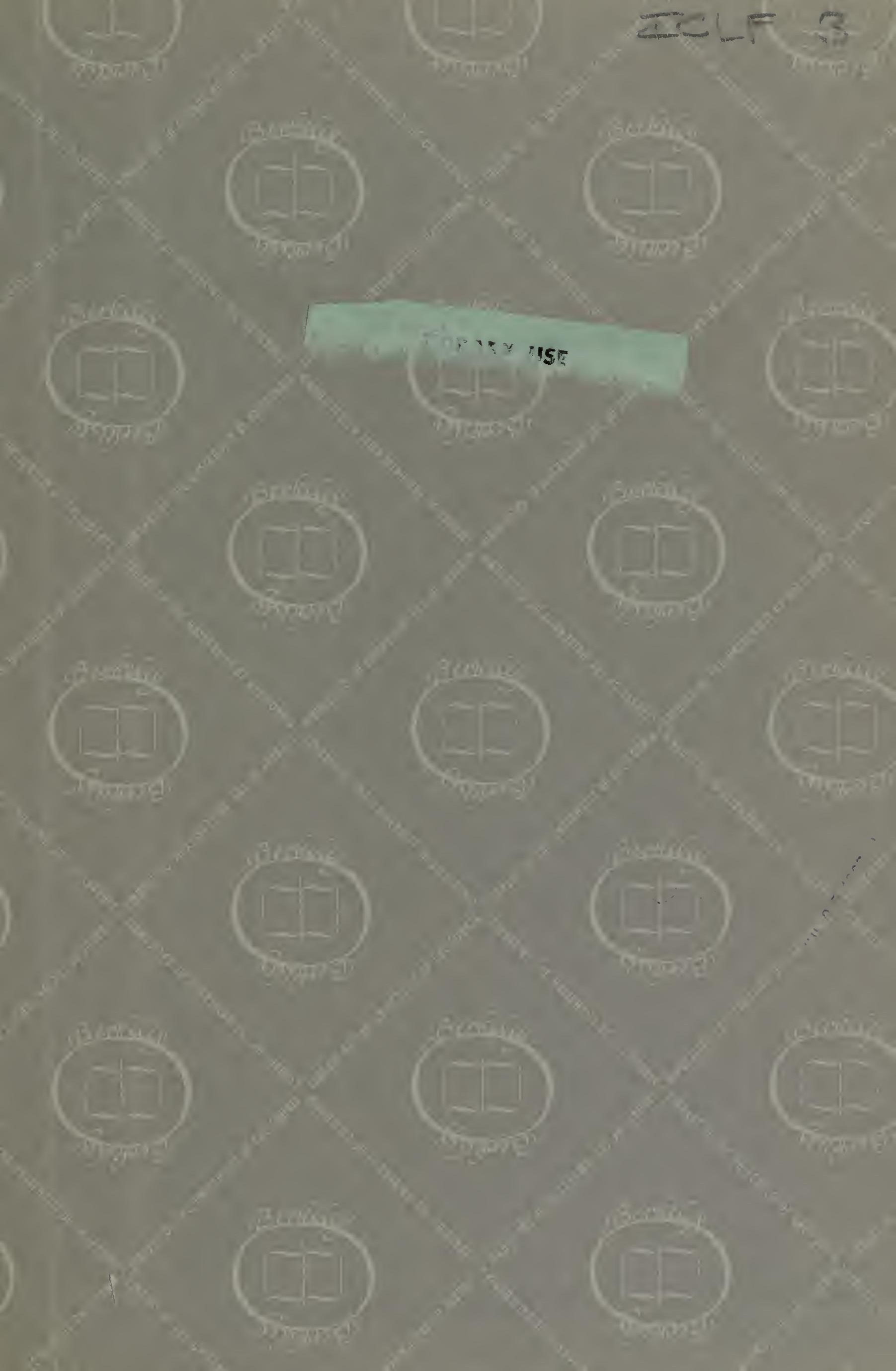




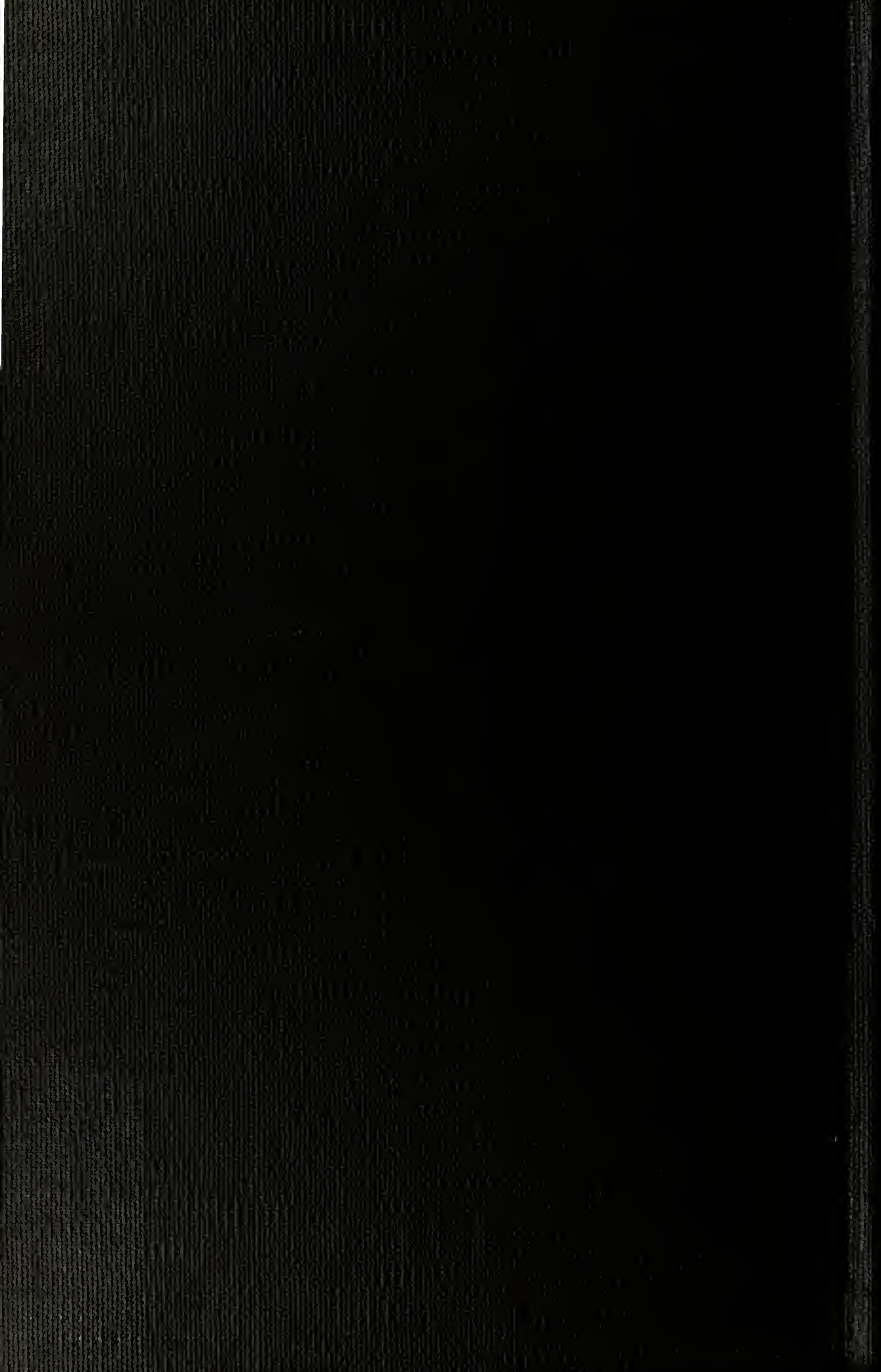

